\title{
ВЛИЯНИЕ ИДЕНТИЧНОСТИ НА ПАТРИОТИЧЕСКИЕ ЧУВСТВА СТУДЕНЧЕСКОЙ МОЛОДЕЖИ В ТРАНЗИТИВНОМ ОБЩЕСТВЕ
}

\begin{abstract}
В статье «Влияние идентичности на патриотические чувства студенческой молодежи в транзитивном обществе» Чернова Л.Е. анализирует результаты собственного социологического исследования патриотизма и идентичности студенческой молодежи Восточной Украины в период трансформации украинского общества. Опрос проведен в начале политического кризиса в Украине в декабре 2013г. Всего опрошено 700 студентов Приднепровской государственной академии строительства и архитектуры г. Днепропетровска (Юго-Восточная Украина). В инструментарии в качестве индикаторов использованы типы идентичности международного проекта ENRI-East «Нации между государствами вдоль новых границ Европейского Союза: европейская, национальная и региональная идентичности» и методика социальной категоризации Дж.Тернера. Сознание студентов оказалось противоречивым с разновекторными намерениями. Лидируют домодерные модели, но имеются подвижки в сторону гражданской и постмодерной идентичности, тоже относится и к патриотизму. Патриотизм студентов достаточно устойчивый, но он разного типа и с разным потенциалом мотивации участия в реформировании страны. С помощью корреляционного анализа выявлена прямая взаимосвязь между типом идентичности и уровнем выраженности и типом патриотичных чувств. Эти два фактора в комплексе обуславливают оценку экономической и политической ситуации, жизненные планы и стратегии молодежи. Во мнениях студентов доминируют индивидуалистические установки или пессимистические оценки своих возможностей влиять на развитие страны, что напрямую обуславливает их политическую и социальную активность. Идентичность и убеждения конструируются личностью с предлагаемых обществом репертуаров и сценариев. Главную роль при этом играют первичная социализация (семья), микросреда (студенчество) и СМИ. Обнаружена автономия и противоречивость разных диспозиционных сфер личностного сознания: обще мировоззренческих установок, практических ориентаций и мотивов действия, что характерно для молодежи с маргинальным сознанием и транзитивным обществам.

Ключевые слова: патриотизм, патриотичные чувства, транзитивное общество, идентичность, тип патриотизма, домодерный, модерный, постмодерный типы идентичности, модель и уровень патриотизма, жизненные планы молодежи, социальная активность.
\end{abstract}

Цель статьи рассмотреть влияние типа идентичности на патриотические чувства и жизненные планы студенческой молодежи на основе социологического

\footnotetext{
${ }^{1}$ Доцент Любовь Чернова, кандидат философских наук, доцент каф. философии и политологии Приднепровской государственной академии строительства и архитектуры, Украина, e - mail: postmaster@mail.pgasa.dp.ua
} 
опроса студентов Приднепровской академии строительства и архитектуры г. Днепропетровска, Украина 2 .

Актуальность темы исследования. Политический кризис украинского общества зимой 2013-2014гг. возник на почве протестов студенческой молодежи в связи не подписанием Соглашения Украины с ЕС, прежде всего, на Западе страны и в столице. Студенческая молодежь г.Днепропетровска, была более пассивной, хотя так же недовольна властью и мечтала про вступление Украины до ЕС (наши опросы 2007-2012гг.). Причины такой позиции мы решили выяснить, проведя специальное исследование в декабре 2013г.

Особенность социального положения молодежи в еe «промежуточном» (маргинальном) положении в обществе. Маргинальная сущность молодежи отмечалась Г. Маркузе и К. Мангеймом. «Быть молодым значит стоять на краю общества, быть во многих отношениях аутсайдером» ${ }^{3}$. Современные исследователи молодежных субкультур считают это «феноменом вынужденной маргинальности», то есть они хотели бы интегрироваться в общество, но общество не создает для этого условий. Молодежь - своего рода социальный аккумулятор трансформаций, происходящих в обществе, поскольку критично настроена относительно существующей реальности, имеет новые идеи и энергию, особенно необходимые в момент коренных реформ 5 . Молодежь - социальный субъект, способный к инициативе и существенному влиянию на общество. Молодежь желает освободить свои интеллектуальные и физические силы, реализовать свои идеи в социальной практике. Молодежь не только потребитель материальных, социальных и духовных ценностей, она так же их производитель ${ }^{6}$. Студенческая молодежь имеет ряд особенностей, присущих только ей. Она активно участвует в разных формах жизнедеятельности общества, имеет социальный опыт конструирования и реализации жизненных стратегий. Общая деятельность в сочетании с территориальной концентрацией порождает у студенчества общность интересов, групповое самосознание, студенческое самоуправление и активность, специфическую субкультуру и образ жизни. Молодежь так же составляет основную группу потенциальных эмигрантов в поисках лучшей жизни и самореализации, если не может достичь своих целей на Родине, все это мы постарались учесть в своем исследовании.

\footnotetext{
${ }^{2}$ Исследование «Патриотизм студенческой молодежи и идентичность» проведено в Приднепровской государственной академии строительства и архитектуры (г. Днепропетровск) квотно-случайная виборка смешанного типа, квоты по специальностям, курсу/возрасту и гендерной принадлежности пропорциональна структуре генеральной совокупности в декабре 2013г. Всего опрошено 700 чел.

${ }^{3}$ К. Манхейм, Диагноз нашего времени. - / К. Манхейм [Пер. с нем. и англ. М.И. Левина и др.]. - (ЛК: Лики культуры). - М. : Юрист, - 1994, с. 9.

${ }^{4}$ И.М. Ильинский, Молодежь как социальная ценность и фактор перемен. - / Игорь

Ильинский - Кемерово: Издательство КГУ, - 2008, с. 6.

${ }^{5}$ Ibidem, c. 57

6 Роль и значение молодежи в обществе /[Электронный ресурс] // Інтернет журнал JaUkraine.-Режим доступу: http://www.jaukraine.kiev.ua/rol_i_znachenie_molodej_i_ v_obshestve.html.
} 
При разработке инструментария, в качестве методологической базы были выделены три группы факторов: 1) неудовлетворение политикой власти и отсутствие перспектив для себя на Родине - политико-ситуативный фактор; 2) уровень и тип патриотизма, его вариации в сознании студентов мировоззренческий фактор; 3) тип идентичности и оценка своих возможностей учиться или найти работу за рубежом -личный фактор. Фактически, тут проявляют себя разные автономные диспозиционные структуры личности, детерминирующие мотивы и влияющие на решения. Наличие и действие данных факторов проверялось на уровне установок, мнений и практических действий.

Относительно оптимистично оценили наличие в Украине всех возможностей для молодежи $37 \%$ респондентов. Из них $16 \%$ ответили: «у нас возможностей больше, чем было у наших родителей в СССР», а $21 \%$ считает, что: «пока нет, но надежда остается». Столько же студентов были осторожными в оценках: «возможности есть, но не все» $(16 \%)$ или пессимистами: «возможностей нет, и не будет, поэтому лучший вариант - это уехать за границу» $(17 \%)$, именно они строят эмиграционные планы. «Дело не в стране, а в личных способностях и характере» ответили $12 \%$ респондентов - индивидуалистов.Активную позицию: «возможностей нет, но я буду стремиться делать все возможное, чтобы они появились»,- выбрали $10 \%$ респондентов.

Среди наиболее острых проблем в Украине (рейтинговая оценка, макс. 5 балов) студенты назвали алкоголизм и наркоманию молодежи (4,9 б.) Далее следуют: проблема трудоустройства (4,2 б.), пассивности и лени, инфантильности молодежи (4,0 б.), проблема снижения уровня интеллекта нации $(3,7$ б.). То есть студенты достаточно самокритичны. Среди социальных программ, которые они хотели бы видеть в плане реформ в Украине, на первое место вышла проблема трудоустройства (5 б.), преодоление коррупции (4,1 б), равные возможности учебы и работы, разработка стратегического плана развития страны, развитие малого бизнеса, честные выборы и прозрачные процедуры принятия решений (по 3,2 б. каждый пункт). То есть, студенты правильно понимают проблемы страны. Вопрос «Надеетесь ли Вы, что положение в Украине в ближайшие годы улучшится?» выявил соотношение позитивных/ негативных ожиданий от будущего развития страны. Лидируют ответы: «останется таким же, как сейчас» $(32 \%)$ и «трудно сказать» (29\%). Оптимистов уверенных в преобразованиях к лучшему было $21 \%$, а пессимистов, которые предполагали, что станет еще хуже - $18 \%$ (именно последние составляют группу потенциальных эмигрантов). На вопрос: «Насколько улучшения в стране зависят Вас?» на первое место вышла индивидуалистическая, но довольна умозрительная позиция: «хочешь изменить что-то - начни с себя» (34\%). Каждый пятый респондент считает, что от него ничего не зависит; столько же студентов ответили, что контроль в руках власти и олигархов, а простые люди ничего не могут сделать; еще $16 \%$ хотели бы искоренить проблемы, но не знают как. Каждый десятый опрошенный не считает своим долгом решать проблемы страны, - поскольку личных проблем хватает. Вот и причины низкой политической активности наших студентов.Только четверть респондентов участвовали в разовых политических акциях хотя бы 1 раз в жизни; каждый восьмой респондент был волонтером общественных организаций, но прекратил эту работу; каждый пятый не видит смысла участвовать в общественной работе; $8 \%$ респондентов не голосуют на выборах. Только $8 \%$ ходят на акции и мероприятия время от времени по 
приглашению друзей или участвовали в школе в экологическом движении, но сейчас прекратили. Принимают участие в работе общественных организаций или политических партий постоянно - 5\%, еще $4 \%$ опрошенных хотят создать свою организацию, 7\% жертвуют на благотворительность. В целом, четверть студентов совершенно пассивны. Примерно половина опрошенных участвуют в разных формах время от времени или ранее участвовали. Социально активными можно считать лишь 9\% респондентов. В общественно-политичном блоке мнения, установки и поведение студентов совпадают, отражая их гражданскую позицию.

Студенческая молодежь считает «утечку мозгов из страны» следствием: «неудачной политики власти» (политичный фактор) - 36\% респондентов; «неполной модернизации страны, где кадры не могут найти работу» (экономичный фактор) треть респондентов; «неверия в лучшее будущее в Украине»-16\%, те самые, что считали, что перспективы нет и надо эмигрировать; «недостаточного патриотичного воспитания» - 10\% (они своими усилиями хотят улучшать жизнь в стране). Еще $4 \%$ респондентов считают, «утечку мозгов» объективным процессом глобализации. Таким образом, отсутствие перспектив (объективное или субъективное) побуждает молодежь искать счастья за рубежом. Такому мнению способствует стойкий бренд, раскручиваемый СМИ, что за границей жизнь лучше и больше перспектив для молодежи. Все это формирует ориентации молодежи при разработке жизненных планов.

Ответы на вопрос «Что Вы будете делать после окончания вуза?») разделились поровну на тех, кто планирует поехать за рубеж, и тех, кто считает, что на Родине для них больше шансов - «где родился, там и пригодился» (по 17\% каждая группа). Часть опрошенных хотела бы поехать учится за рубеж, но вернутся жить и работать в Украине (15\%). Кроме того, есть студенты, кто хотели бы учиться за границей, но не имеет для этого денег (13\%) или плохо владеет иностранными языками (12\%), потому будут искать работу на Родине. Еще каждый десятый респондент имеет намерения завершить учебу в Украине, а работу искать за рубежом (11\%). «Хотели бы уехать, но близкие против» еще 9\% респондентов. В целом, на уровне планов жить за границей хотели бы $28 \%$ респондентов (опросы прежних лет давали более низкие цифры 17- 23\%). Заграничная жизнь как мечта вряд ли достижимая выявлена еще у $34 \%$ опрошенных. Лишь $32 \%$ студентов предпочитают Украину как место проживания в будущем осознанно, еще $34 \%$ - вынуждено. Ясно, что не все, кто хотел бы реализует планы на практике, но данные не в пользу Украины. Как такие намерения на будущее связаны с патриотизмом?

Патриотизм - моральный и политический принцип, социальное чувство, содержанием которого есть любовь к Родине и готовность подчинять ее интересам свои собственные. Представления о сущности и содержании патриотизма различается у разных социальных групп. Поэтому одни люди считают себя патриотами, а другие себя такими не считают. Патриотизм - особое эмоциональное переживание своей принадлежности к стране /территории или культуре, языку, традициям (этнос) и/или осознание своего гражданства (нация). Наличие объекта патриотизма создает его разновидности ${ }^{7}$ гражданский (страна в целом),

\footnotetext{
${ }^{7}$ С.Н. Артановский. Понятие Родины в его современных модификациях. //Вестник Санкт-
} Петербургского государственного унивесритета культуры и искусств /- сб. научных трудов. 
локальный (отдельный город, поселение), территориальный (область, регион, «малая Родина»), этничный (см.выше), социально-экономический (поддержка экономической независимости страны и патриотизм потребителей), личностный (любовь к своим близким, родным, друзьям, микросреде). Космополитизм позиция «весь мир - моя Родина» или «где мне хорошо, там и Родина», возникает под влиянием глобализации и миграций. Данные типы патриотизма мы использовали как маркеры в инструментарии каждый в отдельности, а в анализе обобщили в три подгруппы: домодерный (этничный и локальный, территориальный типы), модерный (гражданский и социально-экономический) и постмодерный (личностный, космополитичный или региональный). Существует мнение, что патриотизм в эпоху глобализации - это устаревшее понятие и присутствует лишь в транзитивных странах как наследие традиционного сознания и малой мобильности. Типы патриотизма, на наш взгляд, напрямую связаны с типом идентичности личности, особенно социальной, а вместе они влияют на оценку политики власти, перспектив, личные намерения и жизненные планы. Это и стало гипотезой нашего исследования.

На вопрос «Что для вас Родина?» треть студентов ответили - «моя страна» гражданско-политическая версия патриотизма. Личностную трактовку: «Родина это самые дорогие в жизни люди, близкие», - выбрали $16 \%$ опрошенных. «Украинская природа», «место, где родился» можно рассматривать проявлением территориального патриотизма, его выбрали $16 \%$ респондентов. Локальный патриотизм: «Родина - мой город, село»,-присущи еще $15 \%$ опрошенных. Космополитическую позицию предпочли 9\% студентов. Строка в паспорте», устаревшее понятие ответили еще $8 \%$ опрошенных. Итак, домодернистское понимание патриотизма выявлено у трети опрошенных, модернистское еще у трети, постмодернистское у $22 \%$, и лишь у $8 \%$ респондентов патриотические чувства отсутствуют.

Более обезличенная и открытая форма того же вопроса: «продолжите фразу "настоящий патриот - это..." - дал несколько иные пропорции. «Человек, готовый жизнь отдать за независимость и процветание Родины» (модернистский гражданский тип патриотизма) выявлен у $18 \%$ респондентов. «Человек, который честно выполняет свою работу, свой долг» - $14 \%$ респондентов (постмодерный тип) и столько же «человек, что любит и бережет природу» (экологичный домодерный тип). «Хорошо знает язык и культуру своего народа и хочет их сохранить в будущем» $(13 \%)$, «носит национальную одежду и всегда разговаривает на родном языке» $(11 \%)$ (обе позиции домодерный этничный тип). «Гордится Родиною и отстаивает ее интересы даже в эмиграции» (постмодерный тип) - так ответили потенциальные эмигранты $(11 \%)$. «Любит свою Родину и считает ее лучшей в свете» (11\%) (этноморфизм, домодерный тип); «никогда не бросит Родину в трудные часы» $(11 \%)$ (модерный тип), так отвечали те, кто не собирается искать счастья за рубежом, другое - по 3-4\%. Обобщим: домодерную (этничную) трактовку патриотизма дали 49\% (!), модерную - 31\%, постмодерную - 20\% опрошенных. Видна динамика, транзитивность общественного сознания, но с большим запаздыванием. То есть студенческая молодежь постсоветской Украины демонстрирует высокую степень консерватизма и традиционализма в мировоззрении, но более современные установки в практических ориентациях и оценках событий. Патриотизм, по мнению студентов, воспитывается, прежде всего, 
в семье примером родителей и рассказами про предков - 37\%. Далее примерно равные доли по 12\%: роль национального искусства, СМИ и пропаганды, образования, личная общественно - политическая активность. Причиной низкого уровня патриотизма студенты считают разочарование политикой власти (20\%), разобщенностью патриотов (17\%), различиями в понимании патриотизма и путей развития страны (11\%). Таким образом, мировоззренческие установки студенческой молодежи Юго-Восточной Украины достаточно консервативны и противоречивы, и мало отличаются от мнений их родителей. В этом блоке мнения, установки и намерения студентов не совпали.

Для проверки наличия связи между типом патриотизма и типом идентичности мы использовали технологию самокатегоризации Дж.Тернера и идентенты (маркеры), апробированные в международном проекте ENRI-East «Взаимодействие европейской, национальной и региональной идентичностей: Нации между государствами вдоль новых границ Европейского Союза» 8 , выделив: этничную, культурную, политическую (национальную), региональную, локальную (территориальную) и личную идентичности. Эти типы мы так же объединили с процессами трансформации общества: домодерный тип идентичности - этничная и локальная; модерный тип - политико-гражданская(национальная) и культурная; постмодерный тип идентичности - региональная и личная.

Согласно ответам студентов, домодерные типы идентичности в разных вариациях выявлены у $46 \%$ опрошенных. Личный (постмодерный) тип идентичности актуализирован больше, нежели социальный у $24 \%$ респондентов. Малая часть студентов считают себя гражданами мира (космополитизм) - 4\% или европейцами - 3\%, что так же можно отнести к постмодерным типам надэтничной идентичности. Таким образом, постмодерный тип идентичности распространен у трети респондентов. Политический, модерный тип идентичности распространен меньше. Так, «гражданами страны» считают себя лишь 14\% респондентов. Еще 4\% опрошенных определили себя как «советского человека» (что намного ниже такого ответа среди взрослого населения Восточной Украины). Остальные затруднились с ответом. Малый процент гражданской идентичности модернистского типа не соответствует трактовкам политического патриотизма, хотя домодерные и постмодерные позиции идентичности почти полностью совпали с аналогичными типами патриотизма. Это можно пояснить, тем, что такая картина характерна для населения Востока Украины постсоветского периода: мониторинговые опросы населения все 20 лет независимости фиксировали доминирование этнической или территориальной идентичности над гражданско -политической у населения Востока и Юга Украины. Но могут быть и другие пояснения. Здесь проявилась автономия и противоречивость разных диспозиционных сфер сознания личности: общемировоззренческих установок, практичных ориентаций и мотивов действия,

\footnotetext{
${ }^{8}$ F. Pichler, The Making of Identities in Eastern European Border Regions: a Theoretical Framework / Florian Pichler // Materials of the International conference «Regional development challenges of EU border regions in the context of the interaction between the EU and countries of its immediate "neighborhood». - Estonia: University of Tartu, $-2008,-$ p.45-58.
} 
что характерно для молодежи с маргинальным сознанием и транзитивным обществам.

Нами были выявлены корреляционные связи по ключевым вопросам темы, связанным с разными сферами диспозиций личности. Меньше связаны между собой вопросы общего характера в трактовках патриотизма и типа идентичности (коэффициент корреляции на уровне 0,1-0,3), тогда как связь между типом идентичности, оценкою событий в стране и жизненными планами более выражена (коэффициент на уровне - 0,4-0,7). Корреляционный анализ за гендером, возрастом и специализацией не дал существенных различий.

Студенты, выбравшие этническую или гражданско-политическую идентичность близки в своих оценках политики власти, определений Родины и настоящих патриотов. Этническая идентичность порождает склонность к этноморфизму «настоящий патриот считает свою страну лучшей в мире» $(28 \%)$, «готов сделать все для ее процветания» (32\%), бережет культуру и язык (18\%), природу (9\%). Студенты с этничной идентичностью определили Родину - как «моя страна» $(34 \%)$ или Родина для них - это «родные люди» (23\%). Студенты с гражданской идентичностью намерены работать на Родине, но не лидируют в этом. Среди них много и тех, кто считает, что настоящий патриот любит Родину и защищает е интересы, даже живя за границей $(22 \%)$. Возможно это проявление исторической памяти про украинскую диаспору прошлого, а может быть личные планы на будущее. У них больше социального оптимизма в оценках перспектив развития Украины.

Студенты с территориальной идентичностью в три рази чаще определяют Родину как «моя страна» (территория, а не гражданство: $82 \%$ против $34 \%$ и $32 \%$ у первых категорий); в два раза чаще демонстрируют намерения работать и учиться в Украине с мотивацией: «тут свое, родное» (42\% против 19\% и 20\% у первых категорий), несмотря на то, что именно эта группа наиболее пессимистично оценивает возможность позитивных изменений в стране, и менее всего довольна своей жизнью сейчас (63\%, самый высокий показатель от всех групп). Эта группа более категорична и негативна в оценках действий и политики власти на Украине. Как первая группа они демонстрируют склонность к этноморфизму (33\%), настояний патриот «готов сделать все для процветания Родины» (34\%), бережет культуру и язык своего народа (28\%), природу (23\%) и «никогда не покинет ее в тяжелые времена» $25 \%$ этой группы. То есть демонстрируют наивысшую степень патриотизма, но локального типа.

Группы с личностной постмодерной идентичностью были небольшими, потому мы объединили их. Они чаще видят причину отъезда кадров за рубеж в их «неверии в улучшения в Украине» $(25 \%)$, среди них немного выше доля потенциальных мигрантов (26-35\%). В трактовке понятия «Родина» они отвечали в три рази чаще, чем другие группы «это место, где родился» $(30 \%)$ или «устаревшее понятие» (10\%). А настоящие патриоты для них это, прежде всего, люди, которые «честно выполняют свою работу, свой долг» (41\%), «критично относятся к себе, не подчеркивают свои заслуги» $(23 \%)$, защищают интересы Родины даже в эмиграции (25\%), среди них много тех, кто не смогли оценить перспективы изменений в стране или оценили их пессимистично.

Студентов, с надэтничными типами идентичности было совсем мало. Но их нельзя объединять, поскольку одни ориентированы в будущее (7\%), другие - в 
прошлое (4\%). Отметим главные качественные различия во взглядах этой группы от других за типом идентичности. Трактовка патриотизма у них во многом совпадает с другими группами, но они себе патриотами не считают. Интересно, что значительная доля космополитов помехой своему желанию учиться или работать за границей, назвали плохое знание иностранных языков (выше, чем у других категорий). Студенты с советскою идентичностью, более негативно оценивают действия украинской власти (более 65\%), треть из них хотели бы эмигрировать в Россию, но родные - против. Именно они чаще считают понятие Родина устаревшим или «пустым звуком», «строкою в паспорте», но в этой группе больше студентов, довольных своей жизнью сегодня.

Выводы. Таким образом, мы выявили, что сознание студенческой молодежи очень противоречиво с разновекторными намерениями, где лидируют домодерные модели идентичности и патриотизма, которые ретранслирует семья, образование, искусство и СМИ. Модернистские гражданские трактовки патриотизма на втором месте по распространенности в мировоззренческих установках сознания студенческой молодежи Юго-Восточной Украины, но мало распространены в самоидентификации. Наряду с этим, постепенно появляются разные версии постмодернистских индивидуальных и надэтничных интерпретаций под влиянием мировой культуры и глобализации. Патриотизм студентов достаточно устойчивый, но он разного типа и с разным валидным потенциалом мотивации личного участия в реформировании страны и общественной жизни. Выявлена зависимость между типом идентичности и типом патриотизма с трактовкой событий в стране и оценкою перспектив реформ. Конструируя свое индивидуальное сознание и идентичность, студенты опираются на распространенные в обществе сценарии, способы самопрезентации и репертуары, которыми они и руководствуются в процессе принятия решений и построении планов на будущее. Во мнениях студентов доминируют индивидуалистические установки или пессимистические оценки своих возможностей влиять на развитие страны, что напрямую обуславливает их политическую и социальную активность и поведение.

\section{ЛІТЕРАТУРА}

[1] Манхейм. К. Диагноз нашего времени. - / К. Манхейм [Пер. с нем. и англ. М.И. Левина и др.]. - (ЛК: Лики культуры). - М. : Юрист, - 1994.

[2] Ильинский И.М. Молодежь как социальная ценность и фактор перемен. - / Игорь Ильинский - Кемерово: Издательство КГУ, - 2008.

[3] Роль и значение молодежи в обществе /[Электронный ресурс] // Інтернет журнал JaUkraine.-Режим доступу: http://www.jaukraine.kiev.ua/rol_i_znachenie_molodej_i_v_obshestve.html.

[4] С.Н. Артановский. Понятие Родины в его современных модификациях. //Вестник Санкт-Петербургского государственного унивесритета культуры и искусств /- сб. научных трудов. - 2012, -№3, [Электронный pecypc] - Режим доступу: http://cyberleninka.ru/ article/n/ponyatie-rodinysovremennye-modifikatsii.

[5] Pichler F. The Making of Identities in Eastern European Border Regions: a Theoretical Framework / Florian Pichler // Materials of the International conference «Regional development challenges of EU border regions in the 
context of the interaction between the EU and countries of its immediate "neighborhood». - Estonia: University of Tartu, -2008 .

\section{WPŁYW TOŻSAMOŚCI NA PATRIOTYCZNE POSTAWY STUDENTÓW W SPOŁECZEŃSTWIE TRANZYTYWNYM}

W artykule „Wpływ tożsamości na patriotyczne postawy studentów w społeczeństwie tranzytywnym" autorka analizuje wyniki badania socjologicznego patriotyzmu i tożsamości studentów uczelni wyższych we wschodniej Ukrainie w okresie transformacji społeczeństwa ukraińskiego. Badania zostały przeprowadzone na początku kryzysu politycznego na Ukrainie w grudniu 2013 roku. W badaniu ankietowym wzięło udział 700 studentów Państwowej Akademii Budownictwa i Architektury w Dniepropietrowsku (południowowschodnia Ukraina). W instrumentarium badawczym jako wskaźniki wykorzystano typy tożsamości międzynarodowego projektu ENRI - Wschód „Narod między państwami wzdłuż nowych granic Unii Europejskiej: europejska, narodowa i regionalna tożsamości” oraz metoda kategoryzacji społecznej G.Ternera. Świadomość studentów okazała się sprzeczną, o różnie zorientowanych intencjach. Przeważają przedmodernistyczne modele, ale jest postępy w kierunku obywatelskiej i postmodernistycznej tożsamości, co dotyczy również patriotyzmu. Patriotyzm studentów jest dość trwały, ale różnorodny i o różnym potencjale motywacji do udziału w reformowaniu kraju. Przy pomocy korelatywnej analizy ustalono bezpośredni związek między typem tożsamości a poziomem ekspresji i rodzajem uczuć patriotycznych. Te dwa czynniki warunkują ocenę sytuacji gospodarczej i politycznej, plany życiowe i strategie młodzieży. W opinii studentów dominują indywidualistyczne wytyczne lub pesymistyczne oceny własnego potencjału oddziaływania na rozwój kraju, które w sposób bezpośredni determinują ich działalność polityczną i społeczną. Tożsamość i przekonania są kształtowane przez jednostkę z repertuarów i scenariuszy, proponowanych przez społeczeństwo. W tym główną rolę odgrywa socjalizacja pierwotna (rodzina), mikrootoczenie (studenci) oraz media. W wyniku badan ujawniono autonomię i sprzeczność różnych dyspozycyjnych sfer świadomości osobowościowej: wytycznych ogólno światopoglądowych, orientacji praktycznych i motywów działania, co jest charakterystyczne dla młodych ludzi o marginalnej świadomości i tranzytywnych społeczeństw.

Słowa kluczowe: patriotyzm, postawy patriotyczne, społeczeństwo tranzytywne, tożsamość, typ patriotyzmu, przedmodernistyczny, modernistyczny, postmodernistyczny typy tożsamości, model i poziom patriotyzmu, plany życiowe młodzieży, aktywnośc społeczna.

\section{INFLUENCE ON IDENTITY PATRIOTIC FEELINGS OF THE STUDENTS YOUTH IN TRANSITION SOCIETY}

The author gives the analysis of the empirical data of sociological survey obtained as a result of the investigation of patriotism and identity of the student youth in the Eastern Ukraine for the period of the transformation process in the Ukrainian society in the article "The impact of identity on the patriotic feelings of the student youth in transitive society". The survey was conducted at the beginning of the political crisis in Ukraine in December 2013. There were surveyed a total of 700 students of Prydniprov'ka State Academy of Civil Engineering and Architecture, Dnepropetrovsk. The types of identity international project ENRI-East 2009-2011 (European, National and Regional Identities) and methodic of the social categorization J.Turner used as indicators in the toolkit of the survey. Consciousness of students is controversial proved with differently oriented intentions. Leading pre-modern model, but there are moves towards civil and postmodern identity, this also applies to patriotism. Patriotism of students fairly stable, but it is of different types and with different 
potential motivation for participation in reforming the country. Correlation analysis revealed a direct correlation between the type and the level of expression of identity and the type of patriotic feelings. These two factors in combination cause the evaluation of the economic and political situation in the country, life plans and strategies of youth. In the opinion of students dominate individualistic installation or pessimistic assessments of their potential to influence the development of the country, which directly determines their political and social activity. Identity and beliefs that any personality follows is constructed using the repertoires proposed y the society. Primary socialization (family), micro environment (student youth) and mass media play the most important role in this process. Autonomy and contradictory different disposition spheres of personal consciousness are founded, which is typical for young people with marginal consciousness and transitive societies.

Keywords: patriotism, patriotic feelings, transitive society, identity, patriotism types, traditional, modern and post modern identity, model of patriotism and level of its intensity, plan of life by student young, social activity.

DOI:10.7862/rz.2014.hss.14

Przesłano do redakcji: marzec 2014

Przyjęto do druku: lipiec 2014 